\title{
Article
}

\section{A Summer Academic Research Experience for Disadvantaged Youth}

\author{
Cathryn Kabacoff, ${ }^{*}$ Vasudha Srivastava, ${ }^{* \dagger}$ and Douglas N. Robinson ${ }^{* \dagger}$
}

${ }^{*}$ Department of Cell Biology, Johns Hopkins School of Medicine, Baltimore, MD 21205; ${ }^{\dagger}$ Department of Chemical and Biomolecular Engineering, Johns Hopkins Whiting School of Engineering, Baltimore, MD 21218

Submitted December 5, 2012; Revised May 11, 2013; Accepted May 20, 2013

Monitoring Editor: Nancy Moreno

\begin{abstract}
Internships are an effective way of connecting high school students in a meaningful manner to the sciences. Disadvantaged minorities have fewer opportunities to participate in internships, and are underrepresented in both science, technology, engineering, and mathematics majors and careers. We have developed a Summer Academic Research Experience (SARE) program that provides an enriching academic internship to underrepresented youth. Our program has shown that to have a successful internship for these disadvantaged youth, several issues need to be addressed in addition to scientific mentoring. We have found that it is necessary to remediate and/or fortify basic academic skills for students to be successful. In addition, students need to be actively coached in the development of professional skills, habits, and attitudes necessary for success in the workplace. With all these factors in place, these youths can become better students, compete on a more level playing field in their internships, and increase their potential of participating actively in the sciences in the future.
\end{abstract}

\section{INTRODUCTION}

Initiated in the Johns Hopkins School of Medicine and the Institute for NanoBioTechnology, the Summer Academic Research Experience Program (SARE) is an outreach effort that provides disadvantaged high school youths with an academically fortified science internship. The goals of SARE are to develop this group of students from the greater Baltimore area into excellent students and eventually professionals in any field, but with a secondary emphasis on science, technology, engineering, and mathematics (STEM) and health-related professions. Baltimore is an area of great need. Approximately $34 \%$ of children in Baltimore City grow up in poverty, which is nearly three times higher than the national rate

DOI: $10.1187 /$ cbe.12-12-0206

Address correspondence to: Douglas Robinson (dnr@jhmi.edu).

(C) 2013 C. Kabacoff et al. CBE-Life Sciences Education (C) 2013 The American Society for Cell Biology. This article is distributed by The American Society for Cell Biology under license from the author(s). It is available to the public under an AttributionNoncommercial-Share Alike 3.0 Unported Creative Commons License (http:/ / creativecommons.org/licenses/by-nc-sa/3.0).

"ASCB ${ }^{\mathbb{R}) " ~ a n d ~ " T h e ~ A m e r i c a n ~ S o c i e t y ~ f o r ~ C e l l ~ B i o l o g y ~}{ }^{\mathbb{R}) " ~ a r e ~ r e g i s-~}$ tered trademarks of The American Society for Cell Biology.
(13\%; University of Wisconsin Population Health Institute, 2012). While reports of graduation rates from the Baltimore community differ (from $\sim 40$ to $\sim 65 \%$, depending on the source), the mayor's office currently reports that $\sim 65 \%$ of students graduate from Baltimore City schools in $4 \mathrm{yr}$ (O'Doherty, 2011), and $\sim 48 \%$ matriculate into 4-yr colleges (Durham and Westlund, 2011). These numbers appear to be much lower for disadvantaged youths (Bridgeland et al., 2006). Situated in the Johns Hopkins School of Medicine in East Baltimore, we are seeking to provide a conduit for promising students to achieve the skills-academic and professional-and the network required to succeed in a profession of their choosing.

It is worth noting that there are several common labels for this group of students, such as underprivileged, at-risk, in-need, marginalized, and disadvantaged. This group of students would prefer to forgo all labels, and we agree with that sentiment. In our program, students are simply referred to as students or scholars. Nevertheless, for the purpose of this article, we use the term "disadvantaged" to avoid confusion, because that is the term currently preferred by professionals in the field.

Competence in science and math prior to college is vital to students' success and persistence from high school to college (Chang et al., 2011). Persistence in college, and perhaps ultimately a STEM career, is also influenced by 
other factors, such as a development of a science identity (Chang et al., 2011) and a growing sense of validation (Hurtado et al., 2011). SARE does many things to help develop a positive science identity. Students are immersed in a culture of science with their own research projects to pursue. Their peer environment includes other students in the program, undergraduate and doctoral students, and postdoctoral fellows. All of these students share similar science goals and can provide a strong socializing force that affects where the students ultimately land and how the students progress in their educational journeys (Chang et al., 2011). In addition, recognition from faculty is critical for a student to maintain an identity as a science person (Carlone and Johnson, 2007). Students feel a sense of validation when an individual within an institution takes an active interest in them, making students feel capable of learning and valued and resulting in the staff and faculty empowering students for success (Hurtado et al., 2011). Validation has been shown to have a positive impact on postsecondary success for disadvantaged youth (Terenzini et al., 1994) and is a key predictor for degree attainment (Rendón, 1994).

Students from different socioeconomic and ethnic backgrounds are not equally represented in STEM careers. The proportion of African-American workers in STEM occupations is only $6 \%$, as compared with the proportion of AfricanAmerican workers in all occupations (12\%; Carnevale et al., 2011). Thus, it is especially important to promote initiatives that could provide internship opportunities for the disadvantaged high school youth, thereby advancing them toward STEM-based careers. Such an outreach program must provide the students with a wide range of experiences beyond their research activities, including academic course work, scientific discussions and presentations, career advice, and professional growth opportunities (Kirwan and Streckman, 2009). Participation in an internship significantly increases the likelihood of graduation in a STEM field at the undergraduate level (Kirwan and Streckman, 2009). Students who had a research experience in high school and whose teachers likewise connected science across the curriculum are also more likely to complete a STEM major than their peers (Gamoran et al., 2011). Thus, our hypothesis is that a high school intervention and support for disadvantaged students will increase their likelihood of selecting a STEM major and graduating from college with a STEM degree.

Our SARE internship program provides a unique opportunity for disadvantaged high school students. SARE internships allow students to try out a science career while learning from professional scientists. Because this is often the students' first work experience, they also need to develop professional skills, attitudes, and habits that are essential to succeed in the work world. Students learn the importance of organization, time management, meeting deadlines, following directions, problem solving, interpersonal communication, and teamwork. Throughout the SARE program, students form strong relationships with faculty and graduate students. These kinds of personal interactions have a large positive impact on retention, persistence to degree, career identification, and student satisfaction at the undergraduate level (Lamport, 1993; Strong, 2009), and we hypothesize that they will also have a positive effect at the high school level. It is hoped that our students, by starting research at an earlier age, will develop an interest in the sciences that will guide their ultimate pursuit of a STEM career.

Demographic factors, which are predictors of college success, include high school math grades, Scholastic Aptitude Test (SAT) scores, and high-quality teaching (Sadler and Tai, 2001; Tai et al., 2006). For successful teaching, classroom practices involve focusing on conceptual understanding and establishing connections between critical concepts (Tai et al., 2006). Thus, the optimal choice of pedagogy must involve active and interactive learning (Seymour, 2001). The SARE program emphasizes making connections, conceptual understanding, and critical thinking. SARE provides a high-quality, problem-solving approach to learning for all students.

In this paper, we describe the SARE program, provide a variety of assessments of the program's effectiveness, and report on the student outcomes to date. We hope to encourage other academic researchers to develop similar programs at their institutions and to shorten the learning curve should investigators decide to pursue such an initiative. By continuing to invest in this crucial group of students, we will promote stronger professionals from disadvantaged minority populations, increase diversity in the STEM and health-related professions, and foster a generation of scientists equipped to help train disadvantaged students. Furthermore, these efforts demonstrate the immediacy that academic sciences can have on local communities, a factor that may be advantageous for the scientific community in a tight funding climate.

\section{METHODS}

\section{Participant Sample}

To date, eight students have participated in SARE, and their work is reflected in this paper. Of these, all are AfricanAmerican, six are male, and two are female. All are disadvantaged in some way and come from Boys Hope Girls Hope (BHGH), Baltimore, or the SEED School, Maryland. To qualify as disadvantaged, students are typically from low-income households, often with one or more parents who are or have been absent or incarcerated and/or have a history of drug abuse. In some instances, students have been homeless or have experienced some mode of abuse.

\section{Data Collection}

All writing assignments (generally the Microsoft Word files [Redmond, WA]) and mathematics tests were archived. If electronic versions of the writing assignments were unavailable, the hard copies were carefully transcribed, so as to ensure that the writing and grammar were not altered. For avoidance of bias, all available writing assignments were analyzed and included in the final assessment. Students submitted final written evaluations, and exit interviews were conducted as one-on-one discussions with the SARE program coordinator. The SARE coordinator took notes and prepared conversation summaries. The same questions were asked of each student in an attempt to reduce bias, and student program evaluations and interviews were archived for assessing program effectiveness. 


\section{Data Analysis}

To analyze writing assignments, we used the Flesch-Kincaid algorithm to assess grade level (Kincaid et al., 1975). To confirm that the Flesch-Kincaid score was an accurate reflection of grade level, we had a professional high school English teacher independently score three essays. The English teacher's score and the Flesch-Kincaid score were within a half-year agreement. We also tested several of our own essays. For example, a perspectives article, written for a college-senior, first-year graduate student level, scored a 17 (comparable with a first-year graduate student) and a biophysics manuscript scored a 23 (comparable with a doctoral scientist). We also examined two essays from other middle school students, which scored at or above grade level. Thus, we concluded that the Flesch-Kincaid provided an objective assessment of the students' writings. After assessing all student essays, we plotted the Flesch-Kincaid scores as a function of the week number of the summer program using KaleidaGraph (Synergy Software, Reading, PA). We fitted each student's set of scores to a linear function, yielding the overall slope, which has the units of grade level/week.

\section{Mentor Satisfaction}

Mentors' satisfaction and benefits were assessed by interviews at biweekly reviews and at the conclusion of the program.

\section{Program Description}

The goal of this program was to provide disadvantaged students with a summer outreach experience that was enriching, challenging, and academically rewarding. Once selected for the SARE program, students were paired with research labs at the Johns Hopkins School of Medicine, where they worked closely with predoctoral or postdoctoral mentors. The research component of the internship was supplemented with an academic classroom component, which accounted for $30 \%$ of their work hours and was intended to fortify their academic and professional skills.

Student Selection. By partnering with BHGH of Baltimore (www.bhghbaltimore.org) and the SEED School of Maryland (www.seedschoolmd.org), we were able to identify candidates who have excellent potential and are most likely to benefit from SARE. Both organizations identify students who typically come from households that may be low-income or that have one or more parents who have been incarcerated or have had drug or significant health concerns. In at least one case, a student had been homeless at some point in his life. BHGH and SEED had already begun the process of stabilizing the family and academic lives of the students. Furthermore, both organizations use similar criteria in student selection. Students are selected based on their willingness to overcome challenges and obstacles despite their life circumstances. Students are also identified as being ambitious and motivated to expand their experience and knowledge base. By having such a preselection in place, we could then focus on students' academic, professional, and personal work-life skills, and because we have such a close partnership with $\mathrm{BHGH}$ and SEED, we gained tremendous support on the home front. Finally, we have been able to provide students a $\$ 3000$ stipend for the 10-wk internship, two-thirds of which we stipulate to go toward each student's college fund. The stipends help ensure that our program has a long-lasting impact on each student's career development, plus we have found that this is important to encourage qualified students to participate in the program, because many need to work for income during the summer.

Methodology and Time Line of Program Implementation. We requested applications from potential students during March and April. On receipt, the applications were evaluated based on the students' grades and level of care seen in the preparation of the application. Students were then invited for an interview in which they were assessed by doctoral and postdoctoral trainees. Once selected, the students were invited to participate in the program. Between admission and the start of the program, we collected additional academic information regarding students' areas of strengths and weaknesses from BHGH and SEED, as well as the students' teachers, to begin to determine the students' academic needs. The students also were given in-house, preassessment tests in math and writing during the first week of the program; these were used to develop individualized academic programs. Concurrently, students began working in the research labs with their doctoral or postdoctoral mentor.

\section{Program Components}

Research Component. Students were placed in research labs in the basic science departments at Johns Hopkins School of Medicine, where they participated actively in a research project for $10 \mathrm{wk}$ under the direct supervision of a doctoral student or postdoctoral fellow. These labs represented several disciplines, including biochemistry, genetics, neuroscience, cell biology, and pharmacology. The topics researched included: cell division, chemotaxis, retinal and neural development, epigenetics, membrane trafficking, and chemical biology. Students learned about the lab's science; learned how to conduct research, including thinking critically and designing and performing experiments; and learned how to interact professionally with graduate-, postdoctoral-, and faculty-level researchers. Complete immersion in the lab culture included participating in lab meetings and journal clubs (in which each student presented a current research paper) and interacting socially with lab members (most of whom range in age from their early 20 s to mid-30s). Students were challenged intellectually in this environment, often much more so than they had been previously. We also note that although SARE students may work independently, we do not allow them to work unsupervised in research labs. Additionally, in the first week of the program, we have the students take a biosafety training course to help them become aware and respectful of laboratory hazards.

The academic portion and the laboratory portion were integrated, in that much of the writing and mathematics were geared to help provide the students with the skills needed to function in the laboratory (Figure 1). At the end of the summer, the students assembled full scientific poster presentations. Students practiced presenting their posters orally, which generally required several days of practice and rehearsal with their lab members and professor. Finally, the students presented their posters at an open reception attended by scientists from across the medical school campus. This was 


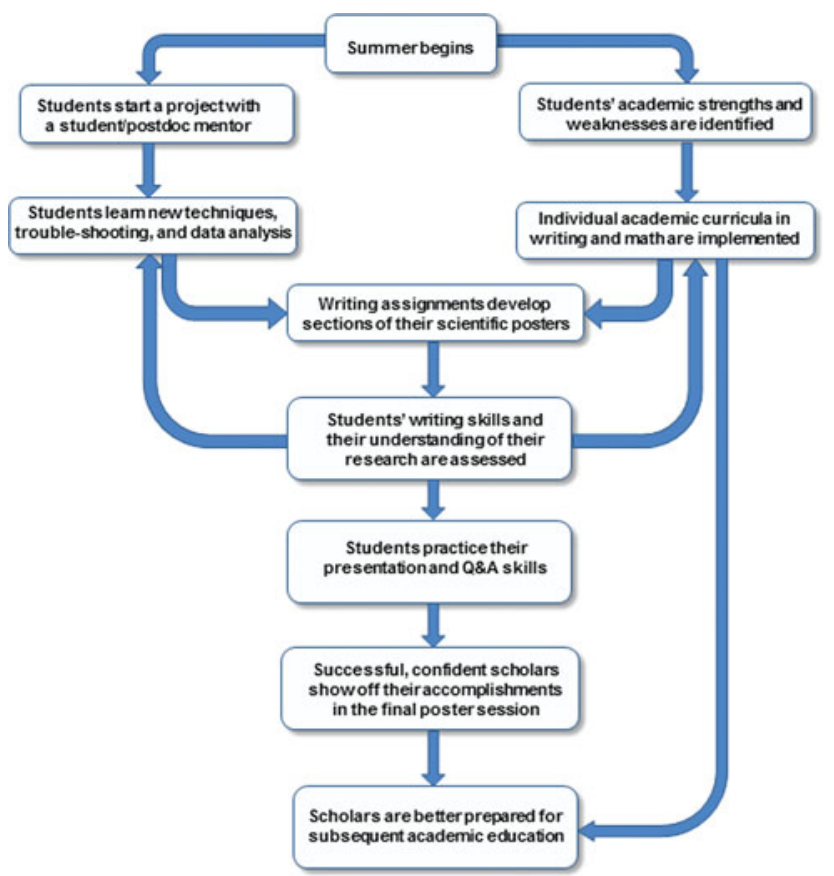

Figure 1. Flowchart depicting the organization and integration of the academic and research portions of SARE.

an anxious time for the students, as they had to show off their new skills, knowledge, and work from the summer. In a few cases, we have had students make novel discoveries, which they got to unveil for the scientific community at this poster presentation.

Professionalism Component. Implicit in each of these activities was an intensive effort to teach, model, and expect a high level of professionalism from each student. Included in professionalism are courtesy, collegiality, punctuality, respect, and a strong work ethic (Supplemental Material). Students learned that their work was important and that they must do a good job, because others will depend on their results. They learned about scientific ethics, which are also relevant for any professional career path. In class, students were taught many topics, ranging from how to write a formal email to the importance of turning off their cell phones and taking off their headsets. We embedded professionalism into every facet of the program.

Students received direct instruction on scientific ethics in the classroom. Lab notebook preparation and maintenance, note keeping, and recognizing and avoiding plagiarism were taught. We also discussed more advanced topics, such as informed consent. For example, last summer, students read Rebecca Skloot's The Immortal Life of Henrietta Lacks. We then organized a "field trip" during which students met with Barbara Migeon, a human geneticist and contemporary of Victor McKusick, and Debra Matthews, a bioethicist, and discussed bioethics from Henrietta's time to the present.

Academic Component: Writing Class. The students participated in a 1-h class four mornings a week in which they worked on scientific and nonscientific writing. The objectives for the writing class can be divided into three sections: writing process, scientific communication and ethics, and scien-

\section{Box 1. Objectives of the SARE Writing Class}

Writing Process

By the end of the summer, students will be able to:

- Write a well-organized paragraph

- Generate ideas for portfolio writing

- Write essays for a variety of purposes

- Write a two to three-page paper reflecting on their summer experience

- Demonstrate an understanding of the full writing process, evidenced in their writing

- portfolio journals

Citing Sources/Ethics

- Cite sources appropriately within the text and in the bibliography

- Identify plagiarism and how to avoid it by paraphrasing and citing appropriate sources

Scientific Writing

By the end of the summer, students will be able to:

- Summarize a scientific journal article

- Understand the components of a laboratory paper

- Understand the writing process and how it applies to scientific writing

- Understand the importance of communicating in writing as a scientist

- Explain the difference between science and nonscience writing

- Create a poster on their summer's scientific work

- Give a 10 -min poster presentation to a mixed scientific and lay audience

tific writing (Box 1). A complete course syllabus is provided in the Supplemental Material.

The writing course began with the basic structuring of a paragraph and progressed to college-level essays on a variety of topics, culminating in a scientific poster presentation and a final reflection essay. During the class, strategies for reading a scientific paper were reviewed. Students wrote either an essay or a section of their poster each week. Additionally, they kept a daily science reflection journal and a vocabulary journal. At the end of the summer, the students gave 1-h scientific poster presentations describing their research. Overall, we provided an opportunity for students to explore their interests in STEM. Our outreach program emphasizes project-based learning focused on exploration of a scientific question.

Academic Component: Mathematics. The objective of the mathematics curriculum for the summer was to review some of the fundamental mathematical concepts and to prepare the students for the coming school year. In the first week of the program, the students were given a preassessment test to evaluate their skill levels in order to customize the curriculum. Based on scores from National Assessment of Educational Progress, it has been reported that $75 \%$ of U.S. eighth graders are not proficient in math (Gamoran et al., 2011). In addition, our students are more at risk, because they only started having intervention at BHGH and SEED in or around 
the sixth grade. For this reason, we composed our preassessment to include elementary school and high school topics, which allowed us to personalize the curriculum to suit individual student requirements. Over the past $4 \mathrm{yr}$, students have often shown weakness in areas such as fractions, decimals, and multiplication tables, topics typically taught in elementary school.

Over the 10-wk duration of the program, different topics were covered in the class, including algebra, plotting and analyzing graphs, statistics, and trigonometry. The use of Microsoft Excel as a tool for calculating and plotting functions was also discussed. The students were constantly challenged to perform. Initially, based on the level of complaints from students, they appeared to be out of their comfort zones. However, they gradually learned how to adjust their work habits and cope with the requirements of the program. Overall, students made some progress in their knowledge of the math topics and found the experience to be beneficial for the next school year.

\section{RESULTS/STUDENT OUTCOMES}

SARE currently uses a portfolio assessment, which includes writing grade level (Flesch-Kincaid formula) and pre- and postassessment tests for evaluating academic progress, student surveys to assess student satisfaction (Supplemental Material), and informal interviews and longitudinal data to assess student outcomes (Supplemental Material).

\section{Research Outcomes}

Students arrived with no previous experience working in a research laboratory and no academic training in biology. We wanted the scholars to learn as much science as they could in a $10-\mathrm{wk}$ period. Students gained a wide variety of research skills, which ranged from cell culture, setting up genetic crosses with Drosophila, molecular biology and DNA manipulation, protein gels and Western blotting, and quantitative cell imaging.

The completion of student scientific posters and oral presentations was the primary manner for evaluating the student outcomes for the research component. Students worked in class and with their mentors to prepare their posters. According to student comments, this was a significant challenge, with some students declaring that this was one of their biggest accomplishments to date. This was illustrated by comments made by the students at their exit interviews:

"I am good at public speaking, but the depth of knowledge necessary for the poster makes it different."

"I didn't think I'd learn so much-in depth-and the bigger picture is so big! At school you have to know certain things, but there's not the depth."

Similar comments were made by all eight students, each expressing pride in his or her poster. They had to organize their posters and their oral presentations in order to present their work in front of a scientific audience, including graduate students, postdoctoral fellows, faculty, and staff. Thus, the SARE students were challenged to answer a broad range of questions about their research. The dynamic nature of the presentations challenged the SARE students to think on their feet, to reason answers to questions that they might not have considered, and to recognize when they did not know the answer. In this context, we were able to observe a high level of critical thinking. Over the course of presenting their posters, students would transform from being nervous to appearing relaxed, confident, and dynamic. To date, all students have produced poster presentations and have left feeling tremendously satisfied with their accomplishment.

\section{Academic Writing Outcomes}

As a preassessment at the onset of the program, the students were asked to pick one essay question from the admissions application for their top college. This allowed us to not only assess their writing levels, but was also a useful exercise for their future. All students scored below grade level in writing, according to the Flesch-Kincaid algorithm (Kincaid et al., 1975). The students' scores ranged from grade levels 5.7 to 6.7 (students were typically rising 10 th to 12 th graders). We also confirmed the Flesch-Kincaid results by having a collection of essays independently scored by a professional high school English teacher; the score given by the teacher was in remarkable agreement with the Flesch-Kincaid score. The English teacher read the essays and, based on his teaching experience, assigned a grade level to each one. These results are qualitative by nature. Our goal was for the students to learn a variety of writing skills and to advance at least one grade level in writing during the summer. We started with the basic structuring of a paragraph and progressed to more complex essays. Students prepared six essays over the 10-wk period that were then analyzed for grade level and quality of content. Six out of eight students showed positive slopes, which ranged from 0.19 to 0.55 grade levels / week (Figure 2 ). The remaining two students showed negative slopes. The trend line presented in Figure 2 was derived from a linear fit for writing levels of all students. Though this analysis provides an overall trend of progress in writing, this should be interpreted with caution, due to the small sample sizes. For the control group, we were provided with summer reflection essays from students from the same organization who had not participated in SARE. Qualitatively, there was marked improvement in the portfolio assessment as well. These essays were corrected and presented to the students for revisions. No grades were given, and the feedback was all qualitative. Students valued the work that they performed in writing and expressed that they thought the improvement would help them in the coming school year. All students commented positively on their writing during their interviews and in student surveys. Responses regarding writing are included below:

Student A (15 yr): With regard to writing, "Essays are not something you sigh upon-they're easy now." The student definitely feels that she has improved and can now write for a deadline. This student's scores increased from grade level 6.7 to 9.2 from the preassessment to postassessment.

Student B (15 yr): He says, "If you want to know if SARE had an effect, just look at my report card next quarter." He is more comfortable in writing essays now. He thinks "it's a good idea to raise the bar in writing." This statement is from a young man who says he is very resistant to writing in school. His scores improved from 5.7 to 5.8 from the pre- to postassessment, but across all 
A

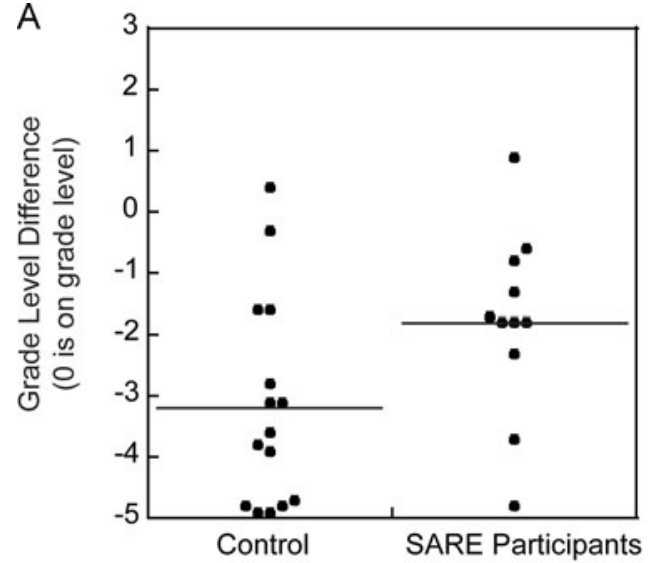

B

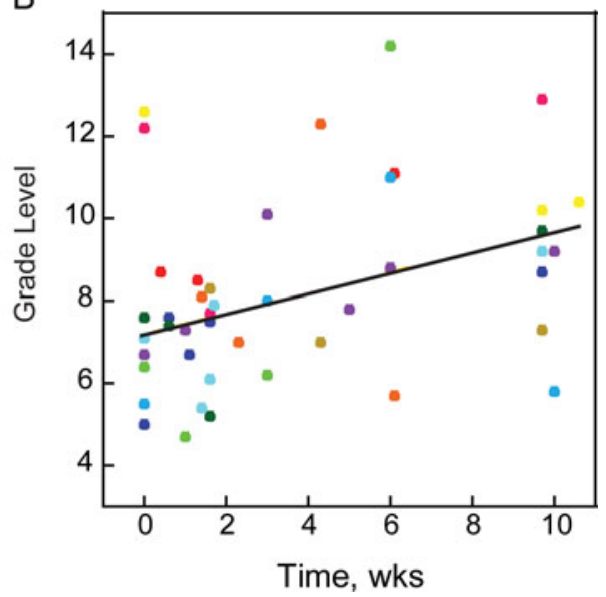

Figure 2. Assessment of impact on writing skills. (A) Grade-level differences of postassessment writing are plotted for SARE students and a control group of similar students not involved in SARE. The grade-level differential is the difference between the measured grade level assessed by Flesch-Kincaid and each student's actual grade level. The assessed writing grade-level difference between the two groups had a $p$ value of 0.06 (as measured by a Mann-Whitney $U$-test). To measure the Flesch-Kincaid grade level, we used the Flesch-Kincaid algorithm that is included with the Word 2007 software package (Microsoft). (B) Trends of all SARE students' writing over a 10-wk period. Each color represents an individual student's writing level. The trend line was derived from a global linear fit and has a slope of 0.2 grade levels/week. Six of eight students showed positive slopes, ranging from 0.19 to 0.55 grade levels/week. Two students showed negative slopes, which ranged from -0.0015 (essentially zero) to -0.22 grade levels/week.

of the essays this student prepared during the summer, he improved approximately two grade levels.

Student C (16 yr): She enjoyed writing weekly essays. She says, "In school writing is really extended." She feels that at our faster pace, she is "more ready for college." Her scores increased from a 6.4 to a 9.2 from the preassessment to the postassessment.

Two of the eight students showed a negative slope in writing. One of these students did not expend effort. For example, regardless of the writing assignment, he submitted the same topic, which was "how he succeeded in life, despite many obstacles." He showed a poor attitude within the lab, had low professional behavior, and tried to do the minimum. He was very bright but displayed a lack of motivation in this program. The second student tried very hard but was starting from such a deficit that we did not measure consistent growth using these metrics. At the start of his $2 \mathrm{yr}$, it was observed by the program organizer that he was unable to read a sixth-grade book and write a complete paragraph. In the $2 \mathrm{yr}$ that we worked with him, he progressed to being able to write a full paper with prompting and guidance. However, he was still unable to succeed independently.

\section{Academic Math Outcomes}

From the preassessment tests, we observed that the students needed remediation in some basic arithmetic and algebraic topics, such as decimals, fractions, and factorization. In-class discussions and additional problem sets were used to revise these concepts. In a comparison of the pre- and postassessments in mathematics, students did not show significant gains. Although their performance improved during quizzes and class work, they appeared to make careless rather than conceptual errors in the postassessment test. The mathematics program was designed to help the students become bet- ter prepared for the coming year. Hence, along with review of previously studied topics, new concepts, such as graphing, statistics, trigonometry, and calculus, were introduced in class based on the students' previous math performance. The students felt they were a step ahead of their peers when these topics were later taught at school. They have also reported that the math practice helped them perform better on standardized tests such as the American College Testing assessment, preliminary SAT, and SAT. The students were continuously challenged to learn new concepts and improve their problem-solving skills. They were encouraged to think critically about the problem instead of simply memorizing the solutions. Much emphasis was also placed on writing down all the steps, which helped reduce the number of careless mistakes made.

\section{Short-Term Professionalism Outcomes}

Each summer, our biggest challenge has been professionalism. At the start of summer, students attend a seminar during which we carefully lay out expectations and define professionalism. We include in the list of professionalism skills: punctuality; reliability; being able to look people in the eye; not texting, emailing, or using a cell phone during a conversation with a colleague or mentor; giving a good handshake; fulfilling commitments and striving for excellence; and exhibiting a high level of integrity in everything one does. Though these are basic social skills, we find that this group of students needs for us to actively teach and consistently enforce them. We give immediate feedback if a student does not behave professionally. We also use biweekly reviews to provide an opportunity to address problems in a timely manner. To date, we have not quantified these behaviors using rubrics, but this could be a useful approach in the future. Overall, learning these professional skills is a process that occurs over 
time, and we hope that our efforts will benefit the students in the long run.

\section{Family Life}

Our students were recruited from well-organized settings (BHGH, Baltimore, and SEED School), and their home lives had already been significantly stabilized by the residential programs. However, simply changing a student's setting does not completely remove the chaos of his or her family life. Some students occasionally had difficulties in their home lives, which affected their focus in SARE. We responded by being supportive and helping them maintain focus in the lab. We also tried to teach the students to view this program as a real work experience in which they needed to learn to compartmentalize (i.e., work problems should remain at work, and home problems should remain at home).

\section{Longitudinal Outcomes}

To date, we have had eight students participate in our program, four of whom are now in college and four of whom are still completing high school but are college-bound. Of the four already in college, one student is a biology/Spanish double major and completed a summer Research Experience for Undergraduates (REU program) at another university. Acceptance into an REU program is enormously competitive (e.g., the acceptance rate in Johns Hopkins University's REU program is typically in the low single-digit percentage $[<5 \%]$ ), and this student, who grew up in inner-city Baltimore, is now firmly planted on a STEM career path. Two of the remaining three college students are majoring in exercise science and criminal justice, respectively, while the final student is still undeclared. The current high school senior has been accepted into five of seven colleges and was wait-listed at the remaining two; this student will major in biology but also has an interest in physical therapy. The final three students are in either their sophomore or junior years of high school.

The SARE experience, regardless of the major, has contributed to the students' successful admission to college. In cases in which we have received feedback directly from a college, SARE participation was considered a strong positive in the student's selection. SARE also helps with the transition to college by providing letters of recommendation for admissions, awards, and scholarship applications. Because of the relationships that the scholars build with their SARE mentors and faculty, SARE provides an ongoing support system for the students. For example, one SARE alumnus was struggling academically during his freshman year of college, and he sought out his SARE mentors for guidance in adjusting his study strategies to the faster-paced academics of college as compared with high school.

Of the four students still in high school, all are heading toward a STEM or health-related college major and career path. To summarize current outcomes, of these eight students, we anticipate that $100 \%$ will go to college and up to $60 \%$ may pursue a STEM or health-related profession.

\section{Benefit to Mentors}

The academic research environment also gains from the outreach program. Benefits to mentors were evaluated through interviews. The interviews were conducted by the program coordinator during biweekly reviews and at the end of the program. The interviews were conducted informally. The final meeting was a roundtable discussion in which all mentors, including student tutors, discussed the program extensively. The mentors, who were doctoral students and postdoctoral fellows, were asked what they felt they have received from the mentoring experience. All agreed on several points: 1) they learned a great deal in mentoring difficult students; 2) they had to learn to keep a much tighter focus and organize their thoughts well, in order to teach at so many different levels; and 3) they felt the experience will make them better mentors for science trainees at any level (including doctoral and postdoctoral). We have also obtained a sense that having the experience of mentoring a disadvantaged student increases the unity within the laboratory group. The effort appears to provide all lab personnel with a greater sense of purpose in the work of the scientific enterprise. Mentors have indicated that they hope to incorporate similar outreach initiatives in their own research programs, which must be a valuable goal to instill in all mentor trainees. Finally, involvement in outreach efforts similar to SARE reduces the ivory tower cocoon, helping the research community to realize immediate impact on the local community.

\section{DISCUSSION}

Nationally, most internship programs are organized informally: either on an ad hoc basis or through business and personal connections (Kirwan and Streckman, 2009). No comprehensive systematic effort exists to place students in meaningful internships, particularly those focusing on increasing the participation of disadvantaged minorities (Kirwan and Streckman, 2009). Indeed, internship positions are most often given to students attending schools (or through school programs) for the academically gifted and talented (National Research Council, 2011).

The SARE program provides internships to disadvantaged youth and provides a rich, intellectually challenging environment with substantial tutoring to help fortify and remediate academic skills. The rationale is that many of these youths may not have been exposed to environments in which creative and critical-thinking skills are emphasized, being smart and working hard are considered "cool," and substantial academic accomplishment is celebrated. Research laboratories within top-flight research universities are naturally constructed with this type of environment. Therefore, one of the many goals in this effort is to leverage this environment to promote stronger critical-thinking skills for this group of students and a sense that they can compete academically and professionally.

The goals of SARE are to help disadvantaged students to develop their academic skill sets and become stronger students who are better able to matriculate in, and ultimately complete, college, and, for a significant fraction of these students, to pursue a STEM or health-related profession. Analysis of our program reveals several interesting observations. First, through the intensive writing program, we are able to advance students' writing levels by $\sim 0.2$ grade levels/week over the $10-w k$ period. This trend was observed for six out of eight students. Interestingly, students who participated for more than 1 yr typically picked up in the second year at the 
same level where they finished the previous year, continuing to improve at the 0.2 grade levels/week rate. These students did not show an advance that can be attributed to the intervening school year. While the data sets are still very small, this raises several questions about why the students are not improving between the end of one summer and the beginning of the next, while SARE appears to promote improvement in a short span of time. To date, the returning students attended private schools with good reputations; yet they did not appear to progress in the area of writing in the intervening school year. We speculate that the schools were unaware of the progress the students had made in SARE and failed to continue to build upon the students' progress. Significantly, SEED requested the students ${ }^{\prime}$ portfolios in math and writing, so they could continue challenging the students. In the future, we will provide students' portfolios for all involved programs and encourage sharing of these portfolios with the schools.

Undoubtedly, the close one-on-one mentoring and the intensive academic environment of an active research lab are collectively conducive to promoting student growth. In a qualitative sense, we observe improved thinking skills among the students. Because students are consistently challenged to support their ideas with substantial evidence and data, students' critical thinking is elevated. We hope that this will help improve the content of their writing and increase their levels of analytical thinking, helping the students in their academic training.

\section{Growth Steps for the Future}

At the end of each summer, we perform a program postmortem in which we identify areas for improvement. This postmortem analysis is conducted as a roundtable discussion with all participating mentors and student tutors. Each year, we identify several new points to be addressed. New for this year is the goal of providing mentor training to help the mentors understand the program and the nature of the students. We had considered including this type of training previously, but we were concerned that we might bias the mentors view of the students. However, we have since learned that this preparation would be beneficial. We will also introduce a 2-wk introduction to biology and chemistry, taught largely by doctoral and postdoctoral students. The planned course syllabus is presented in the Supplemental Material. We think that this will provide a uniform scientific foundation for the scholars.

\section{CONCLUSION}

We have learned that to offer an effective internship for disadvantaged youth, one must develop a comprehensive program that addresses the students' academic, professional, and personal needs. Student selection is critical. Partnering with established outreach organizations, such as BHGH and SEED, increases the potential for impact, because these types of organizations provide support and stability throughout the year. The SARE program then functions to increase that support by helping the students to think of the lab as a community, where "cool," smart people know you, support you, and celebrate your academic and research achievements. Teaching professionalism is essential, and to avoid frustration among the mentors, a mechanism such as the biweekly review is necessary to deal with issues of professionalism as soon as possible. With these considerations put into place, it is possible to have significant impact on the students with quantitative gains in academics and critical-thinking skills. Our program also inspires scientific curiosity and prepares students for a future professional career.

\section{ACKNOWLEDGMENTS}

We thank Craig Montell, Caren Meyers, Alex Kolodkin, Peter Devreotes, Carolyn Machamer, Sean Taverna, and their lab members for opening their labs and mentoring the SARE students. We thank Forrest Spencer for organizing the Henrietta Lacks field trip. We thank Lisa K. Naeger for comments on the manuscript. We also thank Kristy Norbert, Cynthia Burks-Harriel, and the staff at BHGH, Baltimore, and Khalek Kirkland and staff at the SEED School of Maryland for their help with and support for SARE. This outreach effort has been funded by the Johns Hopkins School of Medicine and the Institute for NanoBioTechnology.

\section{REFERENCES}

Bridgeland JM, DiIulio JJ, Morison KB (2006). The Silent Epidemic: Perspectives of High School Dropouts. A report by Civic Enterprises in association with Peter D. Hart Research Associates for the Bill \& Melinda Gates Foundation. www.ignitelearning.com/pdf/ theSilentEpidemic3-06FINAL.pdf (accessed 11 December 2012).

Carlone HB, Johnson A (2007). Understanding the science experiences of successful women of color: science identity as an analytic lens. J Res Sci Teach 44, 1187-1218.

Carnevale AP, Smith N, Melton M (2011). STEM, Washington, DC: Georgetown University Center on Education and the Workforce. http://cew.georgetown.edu/stem (accessed 5 January 2013).

Chang MJ, Eagen MK, Lin MH, Hurtado S (2011). Considering the impact of racial stigmas and science identity: persistence among biomedical and behavioral science aspirants. J High Educ 82, 564596.

Durham RE, Westlund E (2011). A Descriptive Look at College Enrollment and Degree Completion of Baltimore City Graduates, Baltimore, MD: Baltimore Education Research Consortium.

Gamoran A, Betts J, Gollub J, McGee G, McLaughlin M, Means B, Schneider S, Valadex J (2011). Successful K-12 STEM Education: Identifying Effective Approaches in Science, Technology, Engineering and Mathematics, Washington, DC: National Academies Press.

Hurtado S, Cuellar M, Guillermo-Wann C (2011). Quantitative measures of students' sense of validation: advancing the study of diverse learning environments. Enrollment Management J, 53-71.

Kincaid JP, Fishburne RP, Rogers RL, Chissom BS (1975). Derivation of New Readability Formulas (Automated Readability Index, Fog Count, and Flesch Reading Ease Formula) for Navy Enlisted Personnel, Memphis, TN: Chief of Naval Technical Training, Naval Air Station.

Kirwan W, Streckman J (2009). Investing in STEM to Secure Maryland's Future: Final Report of the Governor's STEM Task Force, Annapolis, MD: Governor's STEM Task Force.

Lamport MA (1993). Student-faculty informal interaction and the effects on college student outcomes: a review of the literature. Adolescence 28, 971-990.

National Research Council (2011). Successful K-12 STEM Education: Identifying Effective Approaches in Science, Technology, Engineering, and Mathematics, Washington, DC: National Academies Press. 
O'Doherty R (2011). City Schools Graduation Rate Continues to Climb. www.baltimorecity.gov/OfficeoftheMayor/NewsMedia/ tabid/66/ID/1661/City_Schools_Graduation_Rate_Continues_to _Climb.aspx (accessed 9 November 2012).

Rendón LI (1994). Validating culturally diverse students: toward a model of learning and student development. Innov High Educ 19, 33-51.

Sadler PM, Tai RH (2001). Success in introductory college physics: the role of high school preparation. Sci Educ 85, 111136.

Seymour E (2001). Tracking the processes of change in US undergraduate education in science, mathematics, engineering, and technology. Sci Educ 86, 79-105.
Strong PE (2009). College Students and Faculty in the Residential College Environment: An Investigation of Student Development in the Designed Living-Learning Environment, Saarbrücken, Germany: VDM Verlag Dr. Müller.

Tai RH, Sadler PM, Mintzes JJ (2006). Factors influencing college science success. J Coll Sci Teach 36, 52-56.

Terenzini PT, Rendón LI, Upcraft ML, Millar SB, Allison KW, Gregg PL, Jalomo R (1994). The transition to college: diverse students, diverse stories. Res High Educ 35, 57-73.

University of Wisconsin Population Health Institute (2012). County Health Rankings \& Roadmaps, Baltimore City. www.countyhealthrankings.org (accessed 11 December 2012). 